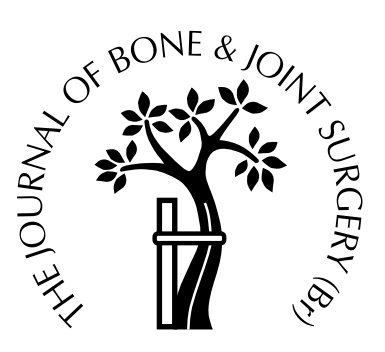

\title{
Survival analysis of the Harris-Galante I acetabular cup
}

\author{
Paul Böhm, Rainer Bösche \\ From the Eberhard-Karls-Universität, Tübingen, Germany
}

W Te reviewed 264 consecutive primary total hip replacements in 244 patients in which the

Harris-Galante I porous-coated acetabular component had been used. The mean follow-up was 95 months (69 to 132). In 221 arthroplasties a $32 \mathrm{~mm}$ ceramic head had been used, and in the other 43 one of cobalt-chrome alloy. There were 124 women and 120 men with a mean age at operation of 56.8 years (21 to 83).

Survival analysis of the acetabular components was performed using the following definitions of failure: 1) infection; 2) removal because of aseptic loosening; 3) removal for any cause; and 4) a worst-case analysis including removal of the cup or infection or loss to follow-up.

Two well-fixed cups had been removed because of deep infection and three, similarly sound cups had been exchanged at the time of femoral revision. None of the acetabular components had required revision for aseptic loosening. After 11 years survival was 97.7\% using the worst-case criterion. Radiological analysis of 187 acetabular components at a mean of 82 months (41 to 132) revealed no case of aseptic loosening. Pelvic osteolysis was seen in only one patient, but was not progressive and showed signs of regression.

The results using these acetabular components are encouraging but the need for regular follow-up remains since complications such as significant wear of the liner, massive osteolysis of the pelvis, aseptic loosening and late infection may increase in the second decade.

J Bone Joint Surg [Br] 1998;80-B:396-403.

Received 8 September 1997; Accepted 25 November 1997

P. Böhm, MD

R. Bösche

Orthopädische Universitätsklinik, Eberhard-Karls-Universität Tübingen,

Hoppe-Seyler-Strasse 3, 72076 Tübingen, Germany.

Correspondence should be sent to Dr P. Böhm.

C 1998 British Editorial Society of Bone and Joint Surgery 0301-620X/98/38349\$2.00
Discussion continues on the merits of using cemented or uncemented cups in total hip replacement (THR). ${ }^{1-3}$ The numerous designs for use without cement include cobaltchrome or titanium alloy, cone-shaped or spherical shape, threaded or press-fit, porous-coated or non-porous-coated, and with no screws or additional transacetabular screws. The most important cause of late failure is osteolysis around the implant, thought to be a result of a cellular response to wear debris. The behaviour of the bearing surfaces is therefore highly relevant. ${ }^{4}$

We have studied our medium-term results using the Harris-Galante I cup which is a modular, spherical, uncemented, press-fit device with a titanium-alloy shell, sintered titanium fibre mesh at the bone-implant interface, and additional transacetabular screws. Most of the features of our study were similar to others using this cup, ${ }^{5,6}$ except that in 221 of the 264 hips we used ceramic femoral heads.

\section{Patients and Methods}

Between July 1985 and April 1997, more than 2000 HarrisGalante cups had been implanted at our hospital. We analysed the results of the first consecutive 264 cups implanted in 244 patients as a primary THR from July 1985 to October 1989. There were 124 women and 120 men with a mean age of 56.8 years (21 to 83). The right hip had been replaced in $121(45.8 \%)$ and the left in $143(54.2 \%)$. Nine men and 11 women had bilateral procedures. The average height of the patients was $167.8 \mathrm{~cm}$ (149 to 198) and the weight $73.0 \mathrm{~kg}$ (44 to 113). On average, the patients were slightly overweight with a mean body mass index of $25.9 \mathrm{~kg} / \mathrm{m}^{2}$ (17.3 to 34.6$)$.

The initial diagnosis was idiopathic osteoarthritis (OA) in 144 hips $(54.5 \%)$, congenital dysplasia in $58(22 \%)$, avascular necrosis in $26(9.8 \%)$, post-traumatic OA in 14 $(5.3 \%)$, protrusio acetabuli in eight $(3 \%)$, rheumatoid arthritis in seven $(2.7 \%)$, OA subsequent to Perthes' disease in three $(1.1 \%)$, OA after infection in two $(0.76 \%)$, and osteoradionecrosis and osseous manifestation of a highly malignant non-Hodgkin's lymphoma in one each. In 44 hips (17\%) a previous operation had been carried out (Table I), and a further seven (2.7\%) had been treated conservatively for congenital dysplasia. 
Table I. Operations undertaken in 44 patients before the arthroplasty

\begin{tabular}{ll}
\hline Operative procedure & $\begin{array}{c}\text { Number of } \\
\text { operations }\end{array}$ \\
\hline Intertrochanteric osteotomy & 23 \\
Osteosynthesis after fracture of the proximal femur & 7 \\
Osteosynthesis after fracture dislocation of the hip & 1 \\
Osteosynthesis after fracture of the pelvis & 4 \\
Pelvic osteotomy or acetabuloplasty & 3 \\
Drilling/fourage operation of the head of the femur & 2 \\
Voss operation & 1 \\
Intra-articular injection of silicone & 1 \\
Operative treatment of non-specific coxitis & 1 \\
Autogenous bone grafting of acetabular cysts & 1 \\
\hline
\end{tabular}

The average diameter of the cup was $54 \mathrm{~mm}$ in women (48 to 64) and $58 \mathrm{~mm}$ in men (48 to 66). The number of screws varied between three and 12 . In the first year, an average of 9.7 screws was implanted, but three years later this had decreased to 5.0. We now use only two, three or four screws.

In 216 of the 264 hips (82\%), an individual cementless Aldinger stem was implanted. ${ }^{7}$ Since we introduced this stem in our clinic it has been combined with the HarrisGalante I cup. In 48 hips, other stems were used. Metal heads were employed in 43 hips in 40 patients, 38 with Müller straight stems (cemented), two with Müller CDH stems (cemented) and three with Weller stems (cemented). The mean age of the 40 patients with metal heads was 64 years at the time of operation. In the other 221 hips a $32 \mathrm{~mm}$ ceramic head was used with 216 Aldinger stems (cementless), four Zweymüller stems (cementless) and one SKT stem (cementless). The mean age of the 204 patients with ceramic heads was 55 years.

Initially, we employed the Aldinger stem, together with the Harris-Galante I cup, principally in young patients, many of whom had hip dysplasia. This may account for the relatively large number of acetabular bone grafts in our series (Fig. 1). Of the 264 THRs, $15 \%$ were associated with a shelf graft, $17 \%$ with a graft for protrusio, and $30 \%$ with grafting to fill bone cysts.

The operations were performed by eight surgeons, all using a transgluteal approach. ${ }^{8}$ Non-steroidal anti-inflammatory agents were used in 124 hips to prevent heterotopic ossification and postoperative low-dose radiation therapy (10 Gy) in 11. In all patients low-dose unfractionated heparin was used for the prophylaxis of postoperative thromboembolism. Before Spring 1996, 17 patients (19 hips) had died from unrelated causes. The average follow-up was 95 months (69 to 132).

Due to the lack of uniformity and objectivity of rating systems ${ }^{9}$ we used the three-factor hip score with separate assessment of pain, functional activity, and movement as recommended by Bryant et al. ${ }^{10}$ The variables of pain, walking distance, limp and range of flexion were graded as recommended. ${ }^{11-13}$ Information concerning clinical followup was obtained by review of the outpatient notes. Some patients were assessed by an orthopaedic surgeon near their home. Patients for whom there was insufficient clinical information were sent a questionnaire, and all who were still living were contacted by telephone. A total of 221 hips was available for assessment.

The preoperative, postoperative and most recent radiographs were evaluated, and evidence of migration assessed as described by Nunn et $\mathrm{al}^{14}$ and Massin, Schmidt and Engh. ${ }^{15}$ The horizontal and vertical position of the cup was measured as was its inclination. Using conventional radiographs, measurement of migration is said to be accurate to within $5 \mathrm{~mm} .{ }^{16}$ Acetabular loosening was defined as a change in the cup angle of more than $5^{\circ} .^{17}$

The appearance of the bone-implant interface was examined for the presence and progression of radiolucent lines in the three zones of DeLee and Charnley ${ }^{18}$ and the development of osteolysis around the socket. Screw breakage and radiological changes around the screws were documented. The state of bone grafts was assessed according to the criteria proposed by Lachiewicz and Hussamy. ${ }^{17}$ Heterotopic ossification was classified according to Brooker et al. ${ }^{19}$ A complete radiological assessment was available in 187 cases $(71 \%)$ at a mean of 82 months (41 to 132$)$. In the remainder some radiographs were not comparable because of different projections, some patients refused to have further films, and in others, recent radiographs were not available. None of these patients, however, reported any problems with their hip.

Survival analysis was performed with different definitions of failure. According to recommendations recently published, ${ }^{20,21}$ we used the life-table method (SAS/STAT and SAS/GRAPH software, version six, 1991; SAS Institute Inc, Cary, North Carolina). The survival curves were calculated with $95 \%$ confidence intervals. ${ }^{22,23}$ As survival analysis was the most important part of this study, we tried to obtain the most accurate information possible. All patients who had not been seen personally at their most recent follow-up were contacted by telephone. For the 17 patients who had died, the last radiographs and clinical information available were evaluated, and their local physician or relatives interviewed. All 264 arthroplasties could be assessed for survivorship analysis and no patient was lost to follow-up.

\section{Results}

Complications. There were no perioperative deaths, but there were 23 intra- or perioperative complications (Table II). In four patients a fracture of the greater trochanter occurred and cerclage was necessary. This complication is a specific problem with this type of individual stem since thorough curettage of the cancellous bone and hollowingout of the greater trochanter are essential to allow correct implantation of the individual stem. The large number of dysplastic hips with high or medium dislocation (Fig. 1) may account for the six patients $(2.3 \%)$ with palsy of the femoral or sciatic nerve. Four out of six lesions recovered 


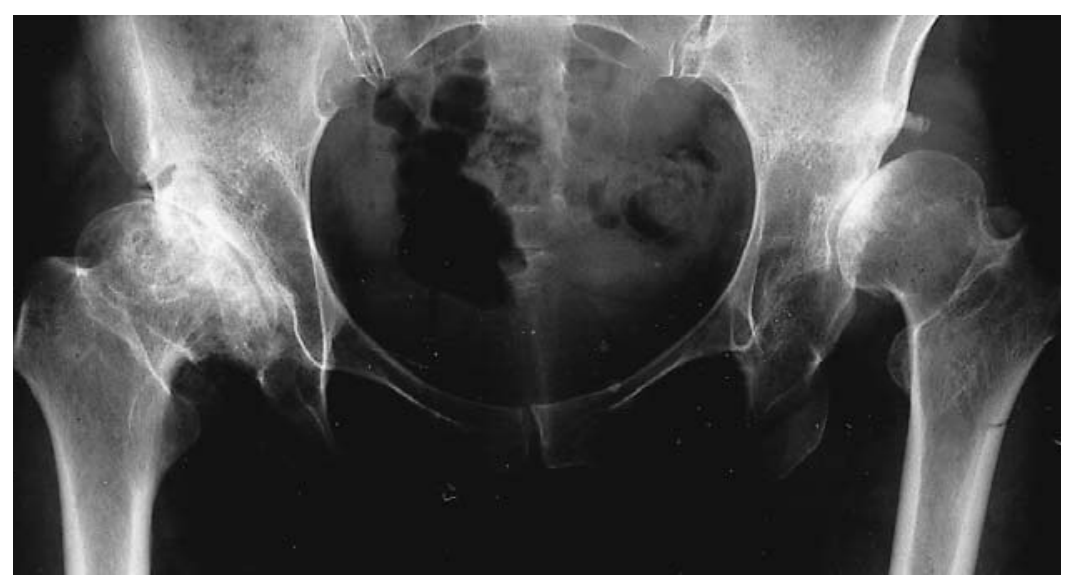

Fig. 1a

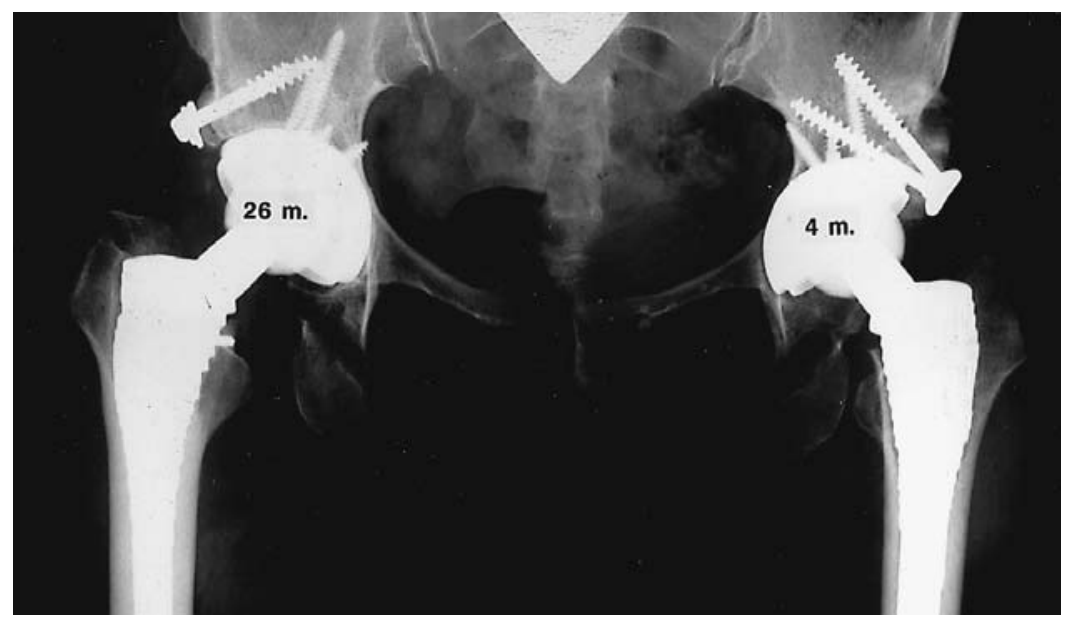

Fig. 1b

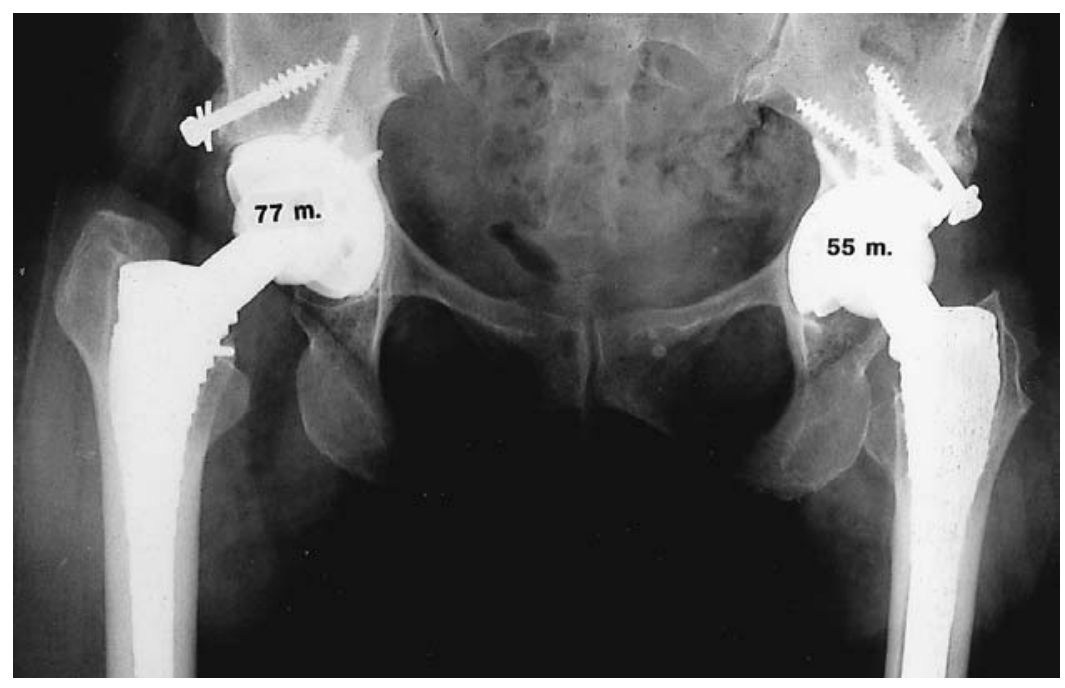

Fig. 1c
Radiological follow-up in a woman with bilateral OA due to congenital dislocation of the hip. At the age of five years an acetabuloplasty had been performed on both sides. Figure 1a - Preoperative radiograph of the patient when aged 51 years. The hip on the right side was more painful. On the left side, the congenital dislocation with a false acetabulum is well seen. Figure $1 \mathrm{~b}$ - Radiograph 26 months after THR on the right side and four months after THR on the left. On both sides, the Harris-Galante I cup was seated in the true acetabulum and autogenous shelf grafting was performed. The acetabular components were combined with an Aldinger individual stem. Figure $1 \mathrm{c}-$ There is a good incorporation of the autografts and no sign of aseptic loosening 77 and 55 months after THR on the right and left sides, respectively. within a few days. In three cases $(1.1 \%)$ there was postoperative dislocation, and one required an open reduction.

\section{Clinical evaluation}

Pain. Before operation $93.2 \%$ of the patients had severe pain, and $6.3 \%$ moderate. Only one patient with ankylosis after tuberculosis of the hip had no pain. At the latest followup, $1.8 \%$ of the patients had severe, $6.8 \%$ moderate and $12.7 \%$ mild pain, while $78.7 \%$ had none. In the four patients with severe pain, aseptic loosening of the Aldinger stem was radiologically evident and revisions were planned. 
Table II. Systemic and local complications which occurred after 23 of the 264 THRs

\begin{tabular}{ll}
\hline Complication & Number \\
\hline Deep-vein thrombosis & 5 \\
Pneumonia & 4 \\
Cerebrovascular accident & 1 \\
Fracture of the greater trochanter & 4 \\
Sciatic palsy (completely resolved) & $3(2)$ \\
Femoral palsy (completely resolved) & $3(2)$ \\
Dislocation & 3 \\
\hline
\end{tabular}

Walking distance. At the latest follow-up, $79.2 \%$ (175/224) hips were in patients who could walk more than $1000 \mathrm{~m}$, and $15.8 \%$ were in those who could walk outdoors but for less than $1000 \mathrm{~m}$. Seven patients $(3.2 \%)$ could walk indoors only and four $(1.8 \%)$ were unable to walk. Two of these four suffered from advanced Parkinson's disease, one woman had had a stroke and the other had undergone stabilisation of the lumbar spine some days before the follow-up and was temporarily bedridden. No patient was immobile because of the THR.

Limp. At the latest follow-up, 57.8\% (126/218) of patients walked with a normal gait, 36.7\% (80/218) had a slight limp and 5.5\% (12/218) a severe limp.

Range of flexion. In $46.3 \%$ (101/218) of hips flexion of more than $105^{\circ}$ was possible, in $43.6 \%(95 / 218)$ the maximum flexion ranged between 75 and $105^{\circ}$, and in $9.6 \%$ $(21 / 218)$ it ranged between 45 and $75^{\circ}$. In one patient the hip was ankylosed in $30^{\circ}$ of flexion due to heterotopic ossification of Brooker class IV. ${ }^{19}$

\section{Radiological evaluation}

Migration of the acetabular component. There was a mean lateral horizontal migration of $0.77 \mathrm{~mm}(-5$ to +5$)$. The mean vertical migration was $0.36 \mathrm{~mm}(-5$ to +5$)$. Within the limits of the method used in our study, ${ }^{16}$ there was no documented migration of the acetabular components.

Inclination. The mean postoperative inclination was $42.0^{\circ}$

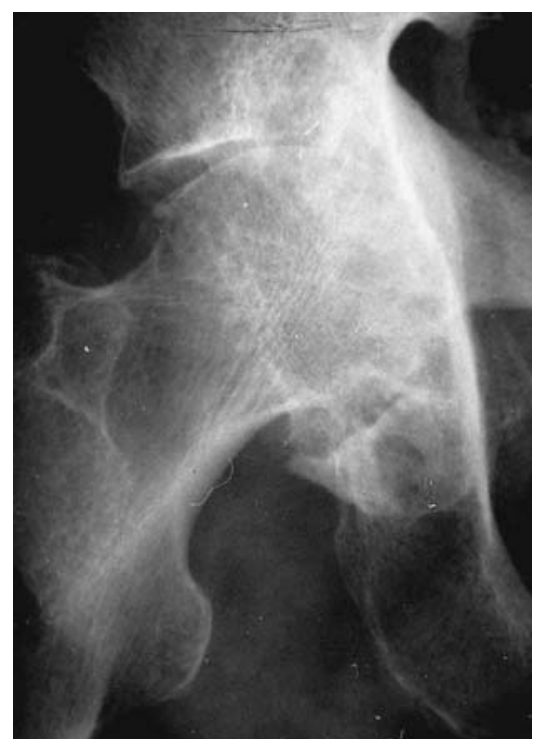

Fig. 2a

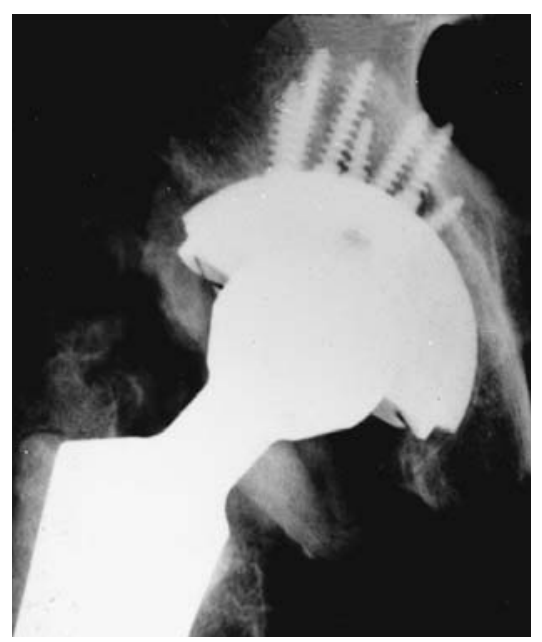

Fig. 2c

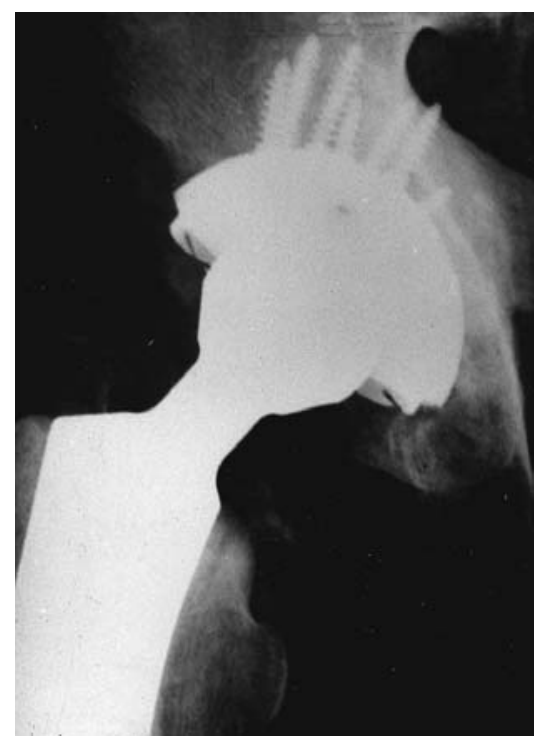

Fig. 2b

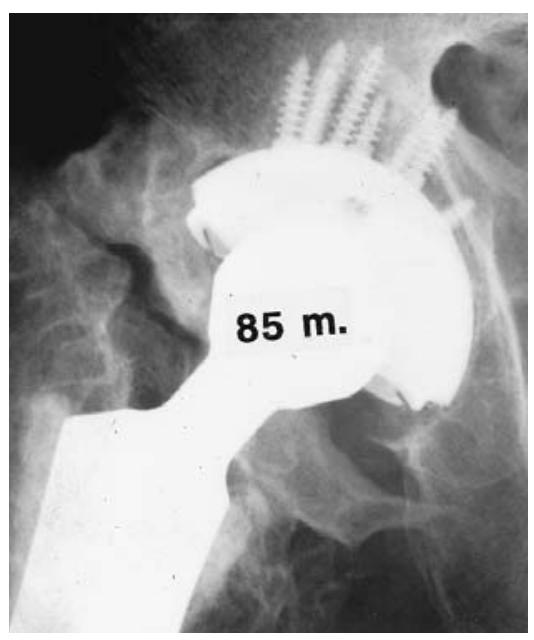

Fig. 2d
Radiological follow-up of the only patient with acetabular osteolysis in the series, a 65-year-old woman with idiopathic OA. Figure $2 \mathrm{a}$ - Preoperative radiograph. Figure $2 \mathrm{~b}-$ Postoperative radiograph after THR and filling of the supra-acetabular cysts with autogenous bone. There was no prophylaxis against heterotopic ossification. Figure 2c Seven months postoperatively osteolysis is clearly visible in zone II. Figure $2 d-$ The patient was able to walk a long distance without any problems and had a good range of movement in spite of the development of Brooker class-III heterotopic ossification 85 months after THR. There was no deterioration of the osteolytic area in zone III, indeed the density of this area was much higher. One year later, when the patient came to the next follow-up examination, she again had an excellent clinical result and refused further radiological examination. 


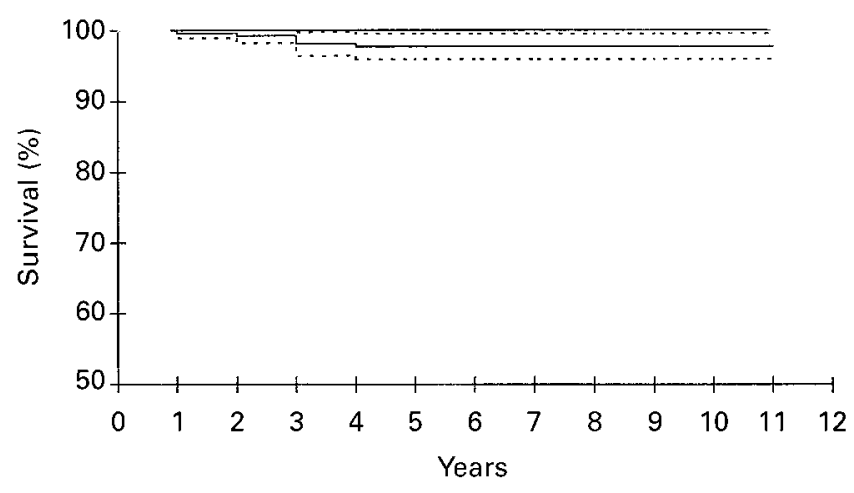

Fig. 3

Worst-case $(n=264)$ survivorship curve of the Harris-Galante I cup, with failure defined as infection and/or cup removal and/or lost to follow-up. the $95 \% \mathrm{CI}$ is shown.

(21 to 63). The inclination of the three hips which had dislocated during follow-up was $46^{\circ}, 48^{\circ}$, and $51^{\circ}$. Compared with the postoperative inclination, the mean inclination at the latest radiological follow-up had increased by $0.12^{\circ}(-5$ to +5$)$. Considering the limits of the method, ${ }^{17}$ there was no case of radiologically documented loosening.

Radiolucencies. There was a radiolucent line in zone I in 17 cups with a maximum width of 0.5 to $1.0 \mathrm{~mm}$, in zone II in five with a maximum width of 0.5 to $1.0 \mathrm{~mm}$, and in zone III in 11 with a maximum width of $1.5 \mathrm{~mm}$. We found a radiolucent line in all three zones in three cups. No radiolucent line had progressed rapidly and some were visible on the first postoperative radiograph. In these, removal of residual articular cartilage may have been incomplete or press-fit was not optimal. Osteolytic areas were seen in the bone adjacent to the titanium-alloy shell in only one case (Fig. 2). No radiolucency was seen around screws and none had broken.

Bone grafts. All bone grafts showed good incorporation and there was no obvious loosening of anchoring screws.

Heterotopic ossification. No heterotopic ossification was seen in $44.9 \%$ (89/187) of hips. This was of Brooker class-I in $21.4 \%$ of hips, class II in $16.6 \%$, class III in $15.0 \%$ and class IV in four $(2.1 \%)$ including the one which was ankylosed. We tested the effect of administering non-steroidal anti-inflammatory agents after operation on the suppression of heterotopic ossification using the Spearman ranking correlation. The risk was significantly reduced ( $p=0.0001)$ by Diclofenac, the Spearman correlation coefficient being -0.394 .

Survival analysis. During the period of follow-up a further operation had been required in 24 of the 264 hips. In 18 the stem was exchanged because of aseptic loosening, and in three of these, the well-fixed cup was also removed because the liner was damaged. These three revisions were all performed in other institutions and in all cases the cups were radiologically sound and good fixation of the cup was documented in the operation report. There were three deep infections, all seen within the first three years (Fig. 3). In one, the infection was cured after exchange of the stem only, but in the other two, both the stems and the well-fixed Harris-Galante acetabular components were removed. In one patient an open reduction was necessary after dislocation of the hip within six months of the original operation. In two patients with limited range of movement due to heterotopic ossification, excision of this new bone was carried out in the second year after operation. In both cases, the original endoprosthesis was left in situ.

We performed survival analysis of the Harris-Galante I cup using infection, removal of the cup because of aseptic loosening, removal of the cup for any cause and worst case (removal of the cup and/or infection and/or lost to followup) as criteria of failure (Tables III and IV; Fig. 3). There were no removals for aseptic loosening, and therefore on this criterion survival was $100 \%$ after 11 years. Considering removal for any cause, there were two cases of deep infection and three of well-fixed cups due to damaged liners when loose stems were exchanged. Our worst-case survival, including all removals and the case of deep infection cured by exchange of the stem, was $97.7 \%$ between the fourth and the 11th years. In comparison with the excellent survival of the Harris-Galante I cup that of the Aldinger individual stem was disappointing, yielding a survival of only $84.9 \%$ (worst-case analysis) after ten years with other patients awaiting revision because of radiologically documented aseptic loosening.

\section{Discussion}

A large number of designs of THR are available, but some with excellent results in preclinical laboratory testing may not perform satisfactorily in clinical use. Results with a

Table III. Survival $(\% ; 95 \%$ CI) of the Harris-Galante I cup and criteria of failure

\begin{tabular}{|c|c|c|c|c|c|}
\hline \multirow[b]{2}{*}{ Criteria failure } & \multicolumn{5}{|l|}{ Survival in years } \\
\hline & 1 & 2 & 3 & 4 & 11 \\
\hline Infection & 100 & 100 & $99.2(98.2$ to 100$)$ & $99.2(98.2$ to 100$)$ & $99.2(98.2$ to 100$)$ \\
\hline $\begin{array}{l}\text { Removal of the cup because of aseptic } \\
\text { loosening }\end{array}$ & 100 & 100 & 100 & 100 & 100 \\
\hline Removal of the cup for any cause & 100 & $99.6(98.9$ to 100$)$ & 98.5 (97.0 to 100$)$ & 98.1 (96.4 to 99.7$)$ & 98.1 (96.4 to 99.7$)$ \\
\hline $\begin{array}{l}\text { Worst case (removal of the cup and/or } \\
\text { infection and/or lost to follow-up) }\end{array}$ & 99.6 (98.9 to 100$)$ & $99.2(98.2$ to 100$)$ & 98.1 (96.4 to 99.7$)$ & 97.7 (95.9 to 99.5$)$ & 97.7 (95.9 to 99.5$)$ \\
\hline
\end{tabular}


Table IV. Life table with failure of THR defined as infection and/or cup removal and/or lost to follow-up (worst case)

\begin{tabular}{|c|c|c|c|c|c|c|c|c|}
\hline $\begin{array}{l}\text { Years since } \\
\text { operation }\end{array}$ & $\begin{array}{l}\text { Number } \\
\text { of hips } \\
\text { at start }\end{array}$ & $\begin{array}{l}\text { Number } \\
\text { withdrawn }\end{array}$ & $\begin{array}{l}\text { Number } \\
\text { at risk }\end{array}$ & $\begin{array}{l}\text { Number of } \\
\text { failures }\end{array}$ & $\begin{array}{l}\text { Annual } \\
\text { failure rate } \\
(\%)\end{array}$ & $\begin{array}{l}\text { Annual } \\
\text { success rate } \\
(\%)\end{array}$ & $\begin{array}{l}\text { Cumulative } \\
\text { success rate } \\
(\%)\end{array}$ & $95 \% \mathrm{CI}$ \\
\hline 0 to 1 & 264 & 2 & 263 & 1 & 0.38 & 99.62 & 100 & 100 to 100 \\
\hline 1 to 2 & 261 & 0 & 261 & 1 & 0.38 & 99.62 & 99.62 & 98.9 to 100 \\
\hline 2 to 3 & 260 & 4 & 258 & 3 & 1.16 & 98.84 & 99.24 & 98.2 to 100 \\
\hline 3 to 4 & 253 & 2 & 252 & 1 & 0.40 & 99.60 & 98.08 & 96.4 to 99.7 \\
\hline 4 to 5 & 250 & 2 & 249 & 0 & 0.00 & 100.00 & 97.69 & 95.9 to 99.5 \\
\hline 5 to 6 & 248 & 3 & 246.5 & 0 & 0.00 & 100.00 & 97.69 & 95.9 to 99.5 \\
\hline 6 to 7 & 245 & 56 & 217 & 0 & 0.00 & 100.00 & 97.69 & 95.9 to 99.5 \\
\hline 7 to 8 & 189 & 85 & 146.5 & 0 & 0.00 & 100.00 & 97.69 & 95.9 to 99.5 \\
\hline 8 to 9 & 104 & 65 & 71.5 & 0 & 0.00 & 100.00 & 97.69 & 95.9 to 99.5 \\
\hline 9 to 10 & 39 & 30 & 24 & 0 & 0.00 & 100.00 & 97.69 & 95.9 to 99.5 \\
\hline 10 to 11 & 9 & 7 & 5.5 & 0 & 0.00 & 100.00 & 97.69 & 95.9 to 99.5 \\
\hline 11 to 12 & 2 & 2 & 1 & 0 & 0.00 & 100.00 & 97.69 & 95.9 to 99.5 \\
\hline
\end{tabular}

minimum of ten years of follow-up ${ }^{24}$ are required. Unfortunately, valid data about clinical outcome are only available for a few designs. The durability of fixation of the cemented femoral component has been demonstrated even in young patients, ${ }^{25}$ and improved cementing techniques have produced a marked reduction in the rate of aseptic loosening. ${ }^{26}$ Loosening on the acetabular side, however, remains a major problem. ${ }^{27}$ Even advocates of cemented fixation recommend this for the cup only in carefully selected patients; those over the age of 60 years or with a life expectancy of 20 years or less. ${ }^{2}$ There is a recent trend towards cementless fixation of the cup, especially in young patients, ${ }^{3}$ but there are few data which support this. ${ }^{5,6,17,28-30}$ There have been disappointing results of the use of threaded screw-ring prostheses. ${ }^{31,32}$ A controlled, randomised study using roentgen stereophotogrammetric analysis showed no major difference in terms of skeletal fixation between a Harris-Galante acetabular component inserted without cement and an all-polyethylene Charnley acetabular component fixed with cement, ${ }^{33}$ but the maximum duration of follow-up was only 49 months. Deterioration of the fixation of cemented acetabular components gradually increases after five years. ${ }^{3}$

There are few reports of the survivorship of uncemented components at ten years or more. In our study, the results of the Harris-Galante I acetabular component were excellent and, according to Murray et al, ${ }^{24}$ it is likely that implants with ten-year survival as good as that of the Charnley design will be as satisfactory in the long term.

The assessment of the functional results is a well-established method for evaluation of THR. It is difficult, however, to report the functional results of only one component of a THR, because it may be impossible to determine which part is responsible for poor performance. The overall state of the patients will vary so much that comparison of assessments of function with the use of different designs of prostheses may not be a suitable means of judging their quality. Considering these limitations, the functional results in the present study were within the scale of THR with cement $^{25,34}$ or a hybrid THR. ${ }^{1}$

Osteolysis due to aggressive granulomatosis in cemented
THR is relatively common. Recently, severe osteolysis of the pelvis has also been reported in association with acetabular replacement without cement. ${ }^{35-39}$ A prospective, randomised, double-blind clinical trial comparing cemented with cementless THR yielded no difference in the prevalence of acetabular osteolysis between the two groups during a follow-up of up to six years. ${ }^{39}$ In another retrospective study osteolysis occurred more often in hips in which the acetabular component had been inserted with cement. $^{38}$ The presence of particulate polyethylene wear resulting in a foreign-body reaction is thought to be the cause of these lesions. Maloney et $\mathrm{al}^{37}$ regarded the holes in the shell as potential pathways for plastic debris to gain access to the implant-bone interface. Most manufacturers then produced prostheses either without holes or with only two or three holes. In our experience the metal shell with multiple holes is extremely versatile, allowing stability of fixation by screws even in dysplastic hips and at revision surgery. We could find no evidence to support the view that the presence of multiple holes increased the risk of pelvic osteolysis.

We had only one case of periacetabular osteolysis. In $84 \%$ of our hips, however, a ceramic femoral head articulated with the polyethylene. Neither Santavirta et $\mathrm{al}^{35}$ nor Maloney et $\mathrm{al}^{37}$ gave information about the material of the femoral head but illustrations showed metal heads. In other relevant studies with high rates of osteolysis, the femoral head was reported to be made of cobalt-chrome or titanium alloy. $^{36,38,39}$ There is a reduced rate of polyethylene wear when a ceramic head is used. ${ }^{4}$ We used a metal head in only 43 out of 264 hips and the mean age of our patients with metal heads was nine years older than that of those with ceramic heads. We had no control group, and therefore we do not know definitely if there is a significant difference between metal/polyethylene and ceramic/polyethylene wear, but the reduced amount of debris could explain the low rate of osteolysis compared with that of other studies. ${ }^{35-39}$ Acetabular osteolysis may increase with time and eventually cause a significant deterioration.

In another series of Harris-Galante cups involving 42 patients aged 50 years or under, with a mean follow-up of 
7.4 years ( 5 to 10 ), six liners had to be replaced due to excessive wear, ${ }^{40}$ but again, there was no information about the material of the femoral head. We had no problems with excessive wear of the liners but this may become a concern, especially in young and active patients. Regular follow-up is needed because, when seen in time, replacement of the liner is a minor procedure in modular acetabular components. In small acetabular components, the use of a $28 \mathrm{~mm}$ femoral head may be advantageous in comparison with a $32 \mathrm{~mm}$ femoral head. 40,41

We did not encounter problems with the screws. The risk of injury to intrapelvic structures is low when anatomical studies are taken into account. ${ }^{42,43}$ Tomkins et al ${ }^{6}$ noted no neurovascular complication in 132 hips with at least one screw penetrating a minimum of two screw threads beyond the inner table of the pelvis.

Although radiological analysis may be useful in survival analyses of prostheses with a high incidence of aseptic loosening and a short follow-up, especially in prospective studies of new concepts of prostheses, it proved of little value in our study. ${ }^{44}$

Using worst-case analysis, the survival of the HarrisGalante I cup was $97.7 \%$ after 11 years. This encouraging outcome, with no aseptic loosening of the acetabular components, suggests that cementless fixation may be equal to or even better than that using cement. Nevertheless, we have to wait another decade before a final comparison with the long-term results of the Charnley prosthesis can be made. Regular follow-up examination remains necessary.

The authors would like to thank Christoph Meisner, MA, (Department of Medical Data Processing, Eberhard-Karls-Universität, Tübingen) for statistical advice.

No benefits in any form have been received or will be received from a commercial party related directly or indirectly to the subject of this article.

\section{References}

1. Harris WH, Maloney WJ. Hybrid total hip arthroplasty. Clin Orthop 1989;249:21-9.

2. Ranawat CS, Peters LE, Umlas ME. Fixation of the acetabular component: the case for cement. J Arthroplasty 1996;11:3-5.

3. Dorr LD. Fixation of the acetabular component: the case for cementless bone ingrowth modular sockets. J Arthroplasty 1996;11:3-5.

4. Black J. Prospects for alternate bearing surfaces in total replacement arthroplasty of the hip. In: Puhl W, ed. Performance of the wear couple BIOLOX forte in hip arthroplasty. Stuttgart: Enke, 1997: 2-10.

5. Latimer HA, Lachiewicz PF. Porous-coated acetabular components with screw fixation: five to ten-year results. J Bone Joint Surg [Am] 1996;78-A:975-81.

6. Tomkins GS, Jacobs JJ, Kull LR, Rosenberg AG, Galante JO. Primary total hip arthroplasty with a porous-coated acetabular component: seven-to-ten year results. J Bone Joint Surg [Am] 1997; 79-A:169-76.

7. Aldinger G, Fischer A, Kurtz B. Computer-assisted production of individual anatomic endoprostheses. Z Orthop 1984;122:733-6.

8. Bauer R, Kerschbaumer F, Poisel S, Oberthaler W. The transgluteal approach to the hip joint. Arch Orthop Trauma Surg 1979;95:47-9.

9. Callaghan JJ, Dysart SH, Savory CG, Hopkinson WJ. Assessing the results of hip replacement: a comparison of five different rating systems. J Bone Joint Surg [Br] 1990;72-B:1008-9.

10. Bryant MJ, Kernohan WG, Nixon JR, Mollan RAB. A statistical analysis of hip scores. J Bone Joint Surg [Br] 1993;75-B:705-9.
11. Merle d'Aubigné R, Postel M. Functional results of hip arthroplasty with acrylic prosthesis. J Bone Joint Surg [Am] 1954;36-A:451-75.

12. Kavanagh BF, Fitzgerald RH Jr. Clinical and roentgenographic assessment of total hip arthroplasty: a new hip score. Clin Orthop 1985;193:133-40.

13. Johnston RC, Fitzgerald RH Jr, Harris WH, et al. Clinical and radiographic evaluation of total hip replacement: a standard system of terminology for reporting results. J Bone Joint Surg [Am] 1990;72-A: 161-8.

14. Nunn D, Freeman MAR, Hill PF, Evans SJW. The measurement of migration of the acetabular component of hip prostheses. J Bone Joint Surg [Br] 1989;71-B:629-31.

15. Massin P, Schmidt L, Engh CA. Evaluation of cementless acetabular component migration: an experimental study. J Arthroplasty 1989;4: 245-51.

16. Sutherland CJ, Wilde AH, Borden LS, Marks KE. A ten-year follow-up of one hundred consecutive Müller curved-stem total hipreplacement arthroplasties. J Bone Joint Surg [Am] 1982;64-A: 970-82.

17. Lachiewicz PF, Hussamy OD. Revision of the acetabulum without cement with use of the Harris-Galante porous-coated implant: two- to eight-year results. J Bone Joint Surg [Am] 1994;76-A:1834-9.

18. DeLee JG, Charnley J. Radiological demarcation of cemented sockets in total hip replacement. Clin Orthop 1976;121:20-32.

19. Brooker AF, Bowerman JW, Robinson RA, Riley LH Jr. Ectopic ossification following total hip replacement: incidence and method of classification. J Bone Joint Surg [Am] 1973;55-A:1629-32.

20. Armitage P, Berry G. Statistical methods in medical research. Second ed. Oxford: Blackwell Scientific, 1987.

21. Murray DW, Carr AJ, Bulstrode C. Survival analysis of joint replacements. J Bone Joint Surg [Br] 1993;75-B:697-704.

22. Senghas RE. Editorial. Statistics in the Journal of Bone and Joint Surgery: suggestions for authors. J Bone Joint Surg [Am] 1992;74-A: 319-20.

23. Dorey F, Nasser S, Amstutz H. The need for confidence intervals in the presentation of orthopaedic data. J Bone Joint Surg [Am] 1993; 75-A:1844-52.

24. Murray DW, Carr AJ, Bulstrode CJ. Which primary total hip replacement? J Bone Joint Surg [Br] 1995;77-B:520-7.

25. MacEwen GD, Floyd GC. Congenital insensitivity to pain and its orthopedic implications. Clin Orthop 1970;68:100-7.

26. Mulroy RD Jr, Harris WH. The effect of improved cementing techniques on component loosening in total hip replacement: an 11-year radiographic review. J Bone Joint Surg [Br] 1990;72-B: $757-60$.

27. Johnsson R, Franzén H, Nilsson LT. Combined survivorship and multivariate analysis of revisions in 799 hip prostheses: a 10- to 20-year review of mechanical loosening. J Bone Joint Surg [Br] 1994; 76-B:439-43.

28. Schmalzried TP, Harris WH. The Harris-Galante porous-coated acetabular component with screw fixation. J Bone Joint Surg [Am] 1992;74-A:1130-9.

29. Martell JM, Pierson RH III, Jacobs JJ, et al. Primary total hip reconstruction with a titanium fiber-coated prosthesis inserted without cement. J Bone Joint Surg [Am] 1993;75-A:554-71.

30. Nakasone $\mathbf{S}$, Norimatsu $\mathbf{H}$, Hamasaki $\mathbf{N}$, et al. A case report of recurrent dislocation of the hip joint with neurofibromatosis. Seikeigeka to Saigaigeka 1989;38:511-4.

31. Fox GM, McBeath AA, Heiner JP. Hip replacement with a threaded acetabular cup: a follow-up study. J Bone Joint Surg [Am] 1994; 76-A:195-201.

32. Bruijn JD, Seelen JL, Feenstar RM, Hansen BE, Bernoski FP. Failure of the Mecring screwing acetabular component in total hip arthroplasty: a three- to seven-year follow-up study. J Bone Joint Surg [Am] 1995;77-A:760-6.

33. Önsten I, Carlsson ÅS, Ohlin A, Nilsson JÅ. Migration of acetabular components, inserted with and without cement, in one-stage bilateral hip arthroplasty: a controlled, randomised study using roentgenstereophotogrammetric analysis. J Bone Joint Surg [Am] 1994;76-A: 185-94.

34. Munuera L, Garcia-Cimbrelo E. The femoral component in lowfriction arthroplasty after ten years. Clin Orthop 1992;279:163-75.

35. Santavirta $\mathbf{S}$, Hoikka V, Eskola A, et al. Aggressive granulomatous lesions in cementless total hip arthroplasty. J Bone Joint Surg [Br] 1990;72-B:980-4. 
36. Buechel FF, Drucker D, Jasty M, Jiranek W, Harris WH. Osteolysis around uncemented acetabular components of cobalt-chrome surface replacement hip arthroplasty. Clin Orthop 1984;298:202-11.

37. Maloney WJ, Peters P, Engh CA, Chandler H. Severe osteolysis of the pelvis in association with acetabular replacement without cement. J Bone Joint Surg [Am] 1993;75-A:1627-35.

38. Zicat B, Engh CA, Gokcen E. Patterns of osteolysis around total hip components inserted with and without cement. J Bone Joint Surg [Am] 1995;77-A:432-9.

39. Nayak NK, Mulliken B, Rorabeck CH, Bourne RB, Robinson EJ. Osteolysis in cemented versus cementless acetabular components. J Arthroplasty 1996;11:135-40.

40. Dunkley A, Eldridge JDJ, Lee MB. Replacement of the acetabulum with the Harris Galante porous cup in the under fifties: 5-10 year results. J Bone Joint Surg [Br] 1997;79-B:Suppl II:219.
41. Willmann G. Modularity: the chance to solve the wear problems in total hip replacement. In: Puhl W, ed. Die Keramikpaarung BIOLOX in der Hüftendoprothetik Stuttgart: Enke, 1996:94-9.

42. Wasielewski RC, Cooperstein LA, Kruger MP, Rubash HE. Acetabular anatomy and the transacetabular fixation of screws in total hip arthroplasty. J Bone Joint Surg [Am] 1990;72-A:501-8.

43. Keating EM, Ritter MA, Faris PM. Structures at risk from medially placed acetabular screws. J Bone Joint Surg [Am] 1990;72-A: 509-11.

44. Ilchmann T, Franzen H, Mjöberg B, Wingstrand H. Measurement accuracy in acetabular cup migration: a comparison of four radiologic methods versus roentgen stereophotogrammetric analysis. J Arthroplasty 1992;7:121-7.

45. Voss C. Die temporäre Hängehüfte: ein neues Verfahren der operativen Behandlung der Coxarthrose und anderer deformierender Hüftgelenkserkrankungen. Verh Dtsch Orthop Ges 1956;43:351-3. 